\title{
Aproveitamento de resíduos da arborização urbana em POMs e sua aceitação pelo público consumidor
}

\author{
Tábuas de corte e servir
}

\author{
Debora Kilngenberg ${ }^{1}$, Adriana Maria Nolasco을 Ananias Francisco Dias Júnior ${ }^{3}$, Luiz Fernando Pereira Bispo ${ }^{4}$, Elias Costa de Souza ${ }^{5}$ \\ ${ }^{1}$ Universidade de São Paulo, Eng. Florestal, Mestranda do PPG em Recursos Florestais, debora.klingenberg@usp.br \\ 2 Universidade de São Paulo, Profa. Dra. do Depto. de Ciências Florestais, amnolasc@usp.br \\ ${ }^{3}$ Universidade Federal do Espírito Santo, Prof. Dr. Do Depto. de Ciências Florestais e da Madeira, ananias.dias@ufes.br \\ ${ }^{4}$ Universidade de São Paulo, Eng. Florestal, luiz.bispo@alumni.usp.br \\ ${ }^{5}$ Universidade de São Paulo, Eng. Florestal, Doutorando do PPG em Recursos Florestais, eliasrem@usp.br
}

\begin{abstract}
RESUMO: As árvores desempenham um importante papel no ambiente urbano e são valorizadas pelos cidadãos por cumprirem diversas funções ambientais, estéticas e até para a saúde pública. Quando há incompatibilidade entre o meio em quem estão plantadas ou por necessidades fitossanitárias, as árvores são manejadas com ações de poda ou remoção, se tornando resíduos, que precisam ser adequadamente destinados pelos seus geradores. Esses resíduos são comumente descartados ou aproveitados em produtos com baixo valor agregado, mas podem ser valorizadas em pequenos objetos de madeira. Nessa pesquisa avaliamos a aceitação do público consumidor quanto a produção de tábuas de corte e de servir alimentos a partir dos resíduos madeireiros de sete espécies comuns na arborização urbana do Estado de São Paulo. Pudemos constatar que a maioria dos participantes da pesquisa acreditam que esse resíduo tem potencial para o aproveitamento e valorização em pequenos objetos de madeira e que seriam bem aceitas no mercado dentro dos padrões e requisitos estabelecidos, com melhorias no design. A preferência foi por tábuas com aspecto mais rústico. Quanto a cor e densidade da madeira, houve aceitação tanto daquelas de cores claras e mais leves quanto das escuras e mais pesadas.
\end{abstract}

PALAVRAS-CHAVE: Valorização de resíduos, resíduos verdes, pequenos objetos de madeira

\begin{abstract}
Trees play an important role in the urban environment and are valued by citizens for fulfilling various environmental, aesthetic and even public health functions. When there is incompatibility between the environment in which they are planted or for phytosanitary needs, the trees are managed with pruning or removal, becoming waste that need to be properly destined by their generators. These residues are commonly discarded or used in products with low added value, but can be valued as small wooden objects. In this research, we evaluated the acceptance of the consuming public regarding the production of cutting and serving boards from the wood residues of seven common species in the urban forestry of the State of São Paulo. We were able to verify that most of the research participants believe that this waste has the potential to be used in small wooden objects and that they would be well accepted in the market within the established standards and requirements, with improvements in the design. The preference was for boards with a more rustic appearance. As for the color and density of the wood, there was acceptance of both softwoods and lighter colors as well as hardwoods and darker ones.
\end{abstract}

KEYWORDS: Waste valorization, green waste, small wooden objects

\section{INTRODUÇÃO}

As árvores no ambiente urbano têm como papel a purificação do ar, redução de impactos da chuva no solo, absorção da poluição sonora, regulação do microclima e consequente diminuição da formação de ilhas de calor (Ransan \& Figueiredo, 2015).

Frequentemente as árvores plantadas nos espaços urbanos precisam passar por tratos silviculturais. Isso ocorre devido a problemas fitossanitários; conflitos entre árvores e formas de ocupação e uso do espaço urbano; falta de planejamento adequado da arborização urbana; risco de queda devido ao ataque de microrganismos ou podas mal conduzidas que desequilibram a copa das árvores; ou não aceitação do cidadão em relação a determinadas espécies.

Os tratos silviculturais geram grandes volumes de resíduos, dentre eles as folhas, galhos, troncos, raízes, flores, frutos e sementes (Meira, 2010; Shi et al., 2013). O gerenciamento desses resíduos é de responsabilidade das prefeituras municipais, quando gerados em áreas públicas, e dos proprietários dos imóveis e das empresas de poda e remoção de árvores que realizam estas atividades em áreas realização organized by apoio institucional supported by
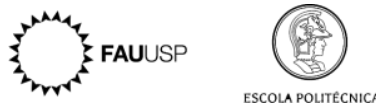
privadas, enfrentando o desafio de destinar esse material corretamente (Faraca et al., 2019; PérezArévalo et al., 2018).

Desde 2010, com a promulgação da Lei $n^{\circ} 12.305$, a Política Nacional de Resíduos Sólidos, os municípios precisam elaborar Planos Municipais de Gestão Integrada de Resíduos Sólidos, definindo procedimentos e regras que devem ser cumpridos pelos cidadãos e empresas para a gestão adequada desses materiais (Brasil, 2012). A mesma lei proíbe a destinação inapropriada de resíduos verdes, o que era prática comum em cidades brasileiras, como queima a céuaberto e disposição em áreas irregulares (Araújo et al., 2018; Brasil, 2012; Fetene et al., 2018).

Existem diversas iniciativas de prefeituras municipais, empresas de poda e outros geradores para o aproveitamento do material em compostagem ou geração de energia (Boumanchar et al., 2019; Meira, 2010). Outras iniciativas indicam o potencial de uso desses resíduos em produtos de maior valor agregado, como por exemplo o aproveitamento em móveis, pequenos objetos de madeira (POMs), painéis de madeira, entre outros (Bispo, 2017; Grohmann et al., 2019; Nowak et al., 2019; Palharini et al., 2018). Dentre os POMs, destacam-se os brinquedos, utensílios de cozinha, objetos decorativos, artigos esportivos e outros objetos de uso pessoal.

Dentre essas possibilidades, os POMs, apesar de não apresentarem uma solução ambiental para o problema de gerenciamento desses resíduos em função de questões relacionadas a compatibilidade da escala de geração de resíduos com a escala de produção dos POMs, possuem grande relevância social pela possibilidade de impulsionar novos empreendimentos, a economia local e a geração de postos de trabalho e renda (Lopes, 2009).

O objetivo dessa pesquisa foi desenvolver uma linha de tábuas de corte e servir alimentos a partir dos resíduos madeireiros da arborização urbana e avaliar sua aceitação pelo mercado consumidor.

\section{MATERIAL E MÉTODOS}

\subsection{Espécies e coleta}

Para o estudo, foram selecionadas sete espécies comuns na arborização urbana do Estado de São Paulo (Klingenberg et al., 2018; Meira, 2010; Silva Filho, 2009) disponíveis naquele momento no município de Piracicaba, SP, sendo elas: sibipiruna Cenostigma pluviosum (DC.) E. Gagnon \& G.P. Lewis., flamboyant - Delonix regia (Bojer ex Hook.) Raf., fícusbenjamin - Ficus benjamina L., oiti - Licania tomentosa (Benth.) Fritsch, canelinha - Nectandra megapotamica (Spreng.) Mez, chapéu-de-sol Terminalia catappa L. e tipuana - Tipuana tipu (Benth.) Kuntze. Foi coletado o material dos galhos de pelo menos três árvores distintas para cada espécie, com dimensões mínimas de 10 centímetros de diâmetro e 70 de comprimento, para viabilizar a produção das peças.

As espécies investigadas possuem densidade média a baixa, variando entre 0,397 a $0,654 \mathrm{~g} / \mathrm{cm}^{3}$ (Klingenberg et al., 2020). Nenhuma madeira apresentou fortes características sensoriais negativas, mas é necessário que em futuras pesquisas seja feita uma análise das propriedades organolépticas como cheiro e gosto, para verificar sua interferência na manipulação de alimentos.

\subsection{Escolha do produto}

Dentre os pequenos objetos de madeira, foram escolhidas, para o estudo, as tábuas de corte e de servir alimentos. Essa decisão foi tomada em decorrência de seu amplo uso pela população, a grande variedade de aplicação (pães, carnes, frios, queijos, vegetais etc.), fácil manufatura e possibilidade de desenvolver vários desenhos diferentes para uma mesma linha de produtos.

Além disso, com pouca tecnologia já é possível produzir tábuas de boa qualidade, sem grande investimento de tempo e recursos, favorecendo a criação de novos empreendimentos e seu uso como base de negócios de cunho social, como cooperativas e associações; servindo, ainda, de base para programas de disseminação da proposta e capacitação para o aproveitamento de resíduos madeireiros da arborização urbana.

Apesar da madeira ser usada há centenas de anos na produção de tábuas de madeira para uso doméstico, recentemente esse tipo de produto vem ganhando importância no mercado por um ideal ecológico de substituição de materiais plásticos e polímeros, além de sua beleza e tradicional usabilidade (Aviat et al., 2016). Também são muito valorizadas em função do seu aspecto estético, sendo expostos como decoração.

A variedade de desenhos e cores das espécies da arborização urbana estudadas, além de defeitos que podem ser incorporados ao projeto do produto tornando-os únicos, favorece bons resultados estéticos, tornando os produtos atrativos.

\subsection{Desenvolvimento}

O processo de desenvolvimento dos produtos foi baseado na definição do público-alvo, de requisitos estéticos, funcionais, normativos, tecnológicos e ambientais para o produto, análise de similares e técnicas de brainstorming. O objetivo dessa etapa da pesquisa foi reunir subsídios para novas ideias e criar soluções.

Definindo os requisitos, a análise de similares forneceu as contribuições necessárias para as tomadas de decisões sobre desenho, processos, acabamentos e valores de mercado, comparando 
com produtos similares fabricados em madeira e outros materiais. Em seguida, foram elaborados esboços dos novos produtos e selecionadas as melhores alternativas para a fabricação de protótipos, considerando os requisitos definidos anteriormente.

\subsection{Prototipação}

Foram confeccionados os protótipos dos produtos utilizando máquinas tradicionais de marcenaria usadas para processamento mecânico da madeira maciça: plaina desengrossadeira e desempenadeira, serra circular estacionária, serra de fita, serra meia esquadria, furadeira, tupia e lixadeira de cinta. Após essas etapas de produção, as peças foram finalizadas com óleo vegetal.

\subsection{Teste de mercado}

Foram realizados testes de preferência e de aceitação. O primeiro é sobre a apreciação pessoal, comumente influenciada pela cultura, além da qualidade do produto, e o segundo é sobre o desejo de uma pessoa adquirir um produto, que varia com os padrões de vida e base cultural e demonstra a reação do consumidor diante de aspectos como preço, aparência e utilidade (Teixeira, 2009).

Os dois testes foram realizados após a produção dos protótipos, utilizando questionários aplicados online e presencialmente, que foram respondidos por potenciais consumidores. A pesquisa online foi realizada com o objetivo de atingir um maior número de indivíduos e públicos de outros Estados, para ter maior abrangência de resultados e foi realizado via Formulários Google, com um padrão elaborado pelos autores, e enviado para diferentes possíveis públicos com fotos e descrição de todos os produtos.

A pesquisa presencial foi realizada após a seleção de um bairro de classe média alta e outro de classe média baixa no município de Americana, SP, e também estudantes de graduação da Escola de Agricultura Luiz de Queiroz, da Universidade de São Paulo em Piracicaba (ESALQ/USP), com seleção aleatória de respondentes. A mesma ficha do questionário online foi utilizada para essas entrevistas.

Os testes foram aplicados em indivíduos de diferentes gêneros; nas faixas etárias de até 20 anos, de 21 a 30 anos, 31 a 40 anos, 41 a 50 anos, de 51 a 60 e acima de 60 anos; e faixas de renda variáveis (sem renda, autônomo, até 2 salários mínimos, de 2 a 4 , de 4 a 10, de 10 a 20 ou acima de 20; considerando o salário mínimo de $\mathrm{R} \$ 880,00)$. Os dados foram tabulados e analisados em função das características de gênero, idade, nível de escolaridade, faixa de renda e local de residência do público, para identificar os segmentos de consumidores que mais se interessaram por esse tipo de produto.

\section{RESULTADOS E DISCUSSÃO}

\subsection{Definição do público-alvo}

O público-alvo é composto por consumidores adultos, interessados em tábuas de madeira para uso doméstico em geral, dispostos a pagar o preço de uma tábua como peça diferenciada à base de resíduos, com desenhos, formas e cores diferentes e exclusivos, de acordo com a característica de cada matéria-prima.

Partiu-se do pressuposto que eles buscam peças com desenhos únicos na madeira para utilização no dia-a-dia ou como objetos decorativos, para servir ou manipular diferentes tipos de alimentos. Esse público aceita pagar mais caro por uma peça diferenciada, com apelo estético e ambiental. Utilizam essas peças no seu dia-a-dia, seja em família ou com convidados em suas casas, ou nos espaços comerciais e institucionais, priorizando sua funcionalidade e estética. Esses consumidores valorizam o material (madeira) e a exclusividade do produto em relação aos outros encontrados no mercado, mantendo as características da aparência rústica e as formas e dimensões diferentes das vendidas normalmente no mercado; mas também valorizam formatos e tamanhos padrão e convencionais, com design mais retilíneo e menos orgânico.

Para atingir esse consumidor, foi necessário entender o que o mesmo procura, tentando alcançálo através de conceitos ambientais e sociais envolvidos (aproveitamento de resíduos da arborização urbana e possibilidade de geração de novos postos de emprego), atendendo suas necessidades a um preço que esse público está disposto a pagar. Além disso, a criação de um produto adequado para o uso, de acordo com sua função satisfazer a necessidade do consumidor.

\subsection{Definição de requisitos}

A seguir foram listados os requisitos principais para o produto em relação ao mercado, estética, funcionalidade, operações e ao meio ambiente (Figura 1). Os requisitos de mercado foram definidos em relação ao que os consumidores de tábuas de corte e servir buscam nesse tipo de produto, sendo muito relevante sua exclusividade, seu preço e seu apelo simbólico e ambiental.

Em relação à estética, a linha rústica manteve alguns defeitos naturais da madeira residual, integrando-os ao desenho do produto, gerando formas diferentes das comuns no mercado; peças únicas com os defeitos incorporados à estética do produto. A linha convencional contou com maior processamento da madeira, não incorporando os defeitos à estética do produto, mas mantendo um produto mais retilíneo e uniforme.

Cada uma das linhas e seus respectivos usos específicos precisaram de dimensões e formas 
adequadas, com presença e ausência de alguns elementos, como cabos ou canais para armazenamento de líquidos.

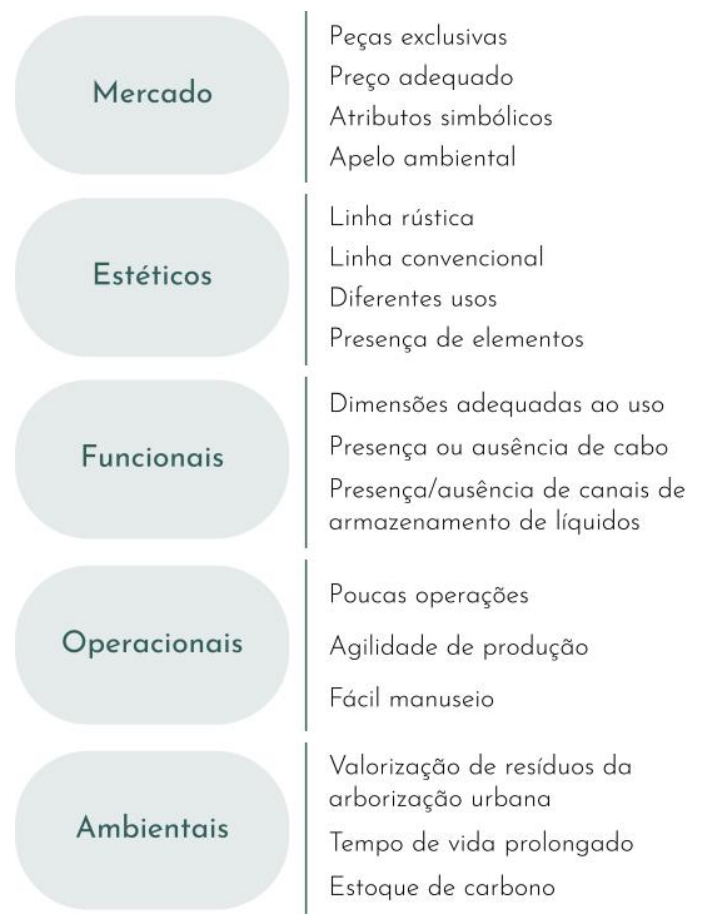

Figura 1: Requisitos para tábuas feitas com os resíduos da arborização urbana por categoria.

Também é interessante que, para quem produza essas peças, haja baixo investimento financeiro e também de tempo, para que a produção seja mais escalável. Além disso, um dos requisitos mais importantes para esse produto é o aproveitamento de resíduos, o tempo de vida prolongado do material e o estoque de carbono.

\subsection{Análise de similares}

A análise de similares mostrou que, no mercado, existem tábuas produzidas com:

1. Bambu, que ganharam espaço no mercado como material lignocelulósico alternativo à madeira;

2. Plástico, que revelaram alguns problemas ao longo do uso, formando muitos vincos e criando um ambiente propício para a proliferação de microrganismos;

3. Altileno ou polietileno fabricadas em material polimérico, que risca menos que o plástico comum, mas em compensação são mais caras;

4. Vidro comum ou temperado, que não são tão bem aceitas devido a características do material, considerado muito frágil e não muito agradável no corte dos alimentos, porém bem higiênicas;

5. Tábuas de madeira com aplicações em cerâmica ou tábuas inteiras do mesmo material, que são mais artesanais e para servir alimentos, não para corte;

6. Madeira, que são tábuas muito comuns no Brasil e as espécies mais utilizadas no país são o pinus, muiracatiara, jatobá, teca e cumaru. Ainda foi possível separá-las em linhas mais rústicas e mais convencionais.

Na tabela 1 é possível observar a faixa de preço encontrada para tábuas de corte e servir de cada tipo de material encontrado.

Tabela 1: Faixa de preço para tábuas de corte e servir produzidas com diferentes materiais.

\begin{tabular}{cc}
\hline Material & Faixa de preço \\
\hline Madeira convencional & $\mathrm{R} \$ 25-\mathrm{R} \$ 180$ \\
Madeira rústica & $\mathrm{R} \$ 50-\mathrm{R} \$ 300$ \\
Bambu & $\mathrm{R} \$ 19-\mathrm{R} \$ 180$ \\
Plástico & $\mathrm{R} \$ 14-\mathrm{R} \$ 40$ \\
Altileno/polietileno & $\mathrm{R} \$ 30-\mathrm{R} \$ 80$ \\
Cerâmica & $\mathrm{R} \$ 50-\mathrm{R} \$ 90$ \\
Vidro & $\mathrm{R} \$ 20-\mathrm{R} \$ 70$ \\
\hline
\end{tabular}

Algumas espécies de madeira usadas e que apresentam preços mais acessíveis, como por exemplo o pinus, podem apresentar algumas desvantagens; no caso dessa espécie, ela pode apresentar manchas mais facilmente e é mais porosa.

Para esse tipo de produto, madeiras mais densas, duras e difíceis de riscar, menos porosas e que tenham maior durabilidade são mais adequadas. Por outro lado, se forem de densidade elevada, há o problema de transporte e manipulação dessas tábuas, que pode inviabilizar o uso dependendo de suas dimensões.

Em relação ao desenho de produto, a maioria das tábuas fabricadas no país possui um desenho típico muito semelhante: retangulares ou circulares, com cabo longo e canal para armazenar líquidos.

Atualmente há maior preocupação com questões ambientais e sociais, e soluções que incorporam outros requisitos tendem a aumentar o valor agregado dos produtos. Tábuas de corte são utilizadas há muito tempo e existe um padrão no mercado, e um produto com design diferente como aqui proposto, pode ganhar visibilidade por ser distinguível, atingindo um público mais específico, que pode adquirir produtos deste tipo.

\subsection{Prototipação}

Os resíduos madeireiros da poda e remoção das árvores no ambiente urbano, por apresentarem características únicas, geraram peças também únicas. Foram criadas duas linhas de produtos, sendo a primeira uma linha mais convencional e outra rústica. A partir dos croquis elaborados anteriormente, foram desenvolvidos os protótipos de tábuas de corte e servir alimentos (Figura 2), ressaltando que estes resíduos possuem formas e tamanhos limitados e únicos, sendo os desenhos adaptados a cada peça. 
(a)

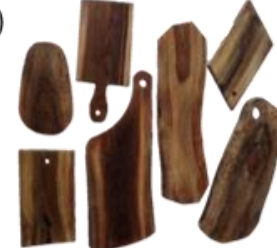

(c)

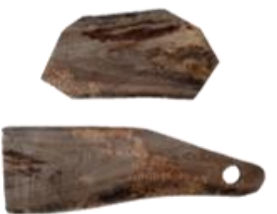

(e)

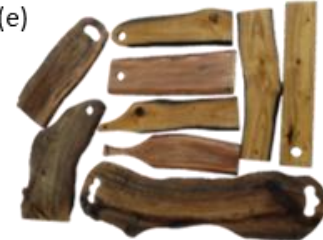

(g)

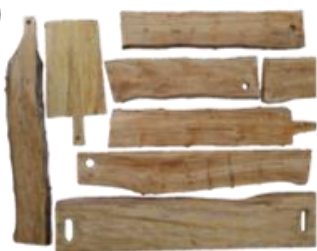

(b)

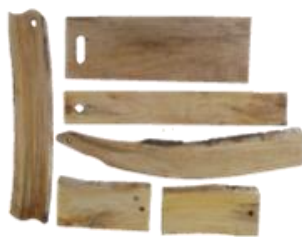

(d)

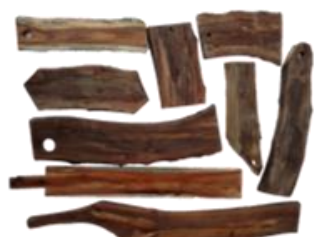

(f)

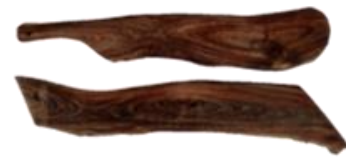

a. Cenostigma pluviosum

b. Delonix regia

c. Ficus benjamina

d. Licania tomentosa

e. Nectandra megapotamica

f. Terminalia catappa

g. Tipuana tipu

Figura 2: Protótipos produzidos a partir dos resíduos madeireiros de sete espécies da arborização urbana.

$\mathrm{Na}$ maioria dos casos foi preferido manter as formas e desenhos naturais da madeira, e para isso, foram feitas adaptações dos modelos às peças de madeira durante a produção.

\subsection{Teste de mercado}

No teste online, foram obtidas 121 respostas e no presencial foram 12, sendo os participantes, em sua maioria, do Estado de São Paulo (Figura 3) e faixa etária entre os 21 e 40 anos de idade.

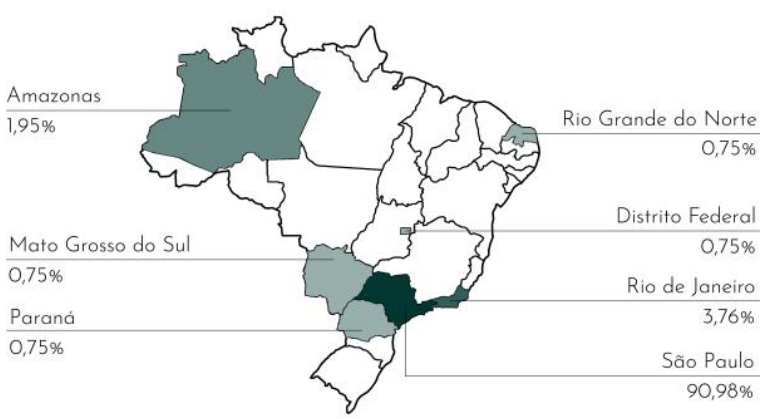

Figura 3: Estado de origem dos participantes do teste de mercado para tábuas de corte feitas a partir de resíduos.

A maioria das respostas foi do público feminino $(66,94 \%)$, seguido do masculino $(32,33 \%)$ e nãobinário $(0,73 \%)$. Os participantes apresentaram rendas variadas, desde sem renda até acima de 20 salários mínimos, este sendo considerado de

$\mathrm{R} \$ 880,00$. A maior parte deles possuía renda de 2 a 10 salários mínimos (73,55\%). Mais da metade dos participantes do formulário online possuíam nível de escolaridade de ensino superior completo $(50,36 \%)$, seguido de ensino superior incompleto $(32,32 \%)$ e pós-graduação (8,94\%), mas também foram englobadas pessoas com ensino fundamental e médio, completo e incompleto.

Em relação à preferência estética das tábuas por espécie, a mais votada foi a sibipiruna (Cenostigma pluviosum), com $51,11 \%$ da preferência dos participantes. As demais seguiram na seguinte ordem de preferência: Delonix regia (12, 01\%), Terminalia catappa (9,03\%), Nectandra megapotamica (9,01\%), Licania tomentosa (8,09\%), Tipuana tipu (6,75\%) e Ficus benjamina (3,73\%).

As justificativas para essas escolhas foram determinadas pela cor, textura, destaque do cerne em relação ao alburno, desenho da madeira, design e formato das tábuas, uniformidade e irregularidades no desenho da madeira.

Apenas a sibipiruna (Cenostigma pluviosum) apresentou nenhum voto "não gostei" entre os questionários online e presenciais. Essa é uma espécie moderadamente pesada e que apresenta coloração distinta entre o cerne e o alburno da árvore, dando esse aspecto bicolor que agradou a muitos. Seu cerne, que tem cor mais escura, chamou a atenção dos respondentes. Entre as duas tábuas preferidas da espécie, uma era da linha rústica e outra da linha convencional (figura 4a).

No caso do flamboyant (Delonix regia), apenas $3,3 \%$ dos participantes não gostaram das tábuas produzidas com essa espécie. Essa espécie possui madeira amarelo claro e densidade baixa. Os modelos preferidos também apresentaram ser um da linha convencional e outro da linha rústica (figura $4 b$ ).

As tábuas de fícus-benjamin (Ficus benjamina) obtiveram a maior proporção de votos "não gostei", totalizando $30,6 \%$ das pessoas. De qualquer forma, a tábua com cabo foi selecionada a tábua preferida (figura 4c).

A madeira é muito leve e apresentou muitas manchas, o que pode ter levado a esse resultado. 0 oiti (Licania tomentosa) apresentou boa aceitação, com apenas $6,6 \%$ de respostas negativas. Essa espécie é de densidade média a baixa e apresenta cor escura com manchas avermelhadas, que formam desenhos que agradaram os respondentes. Entre as preferidas pelo público entrevistado, estavam duas tábuas sem cabo, uma com e outra sem furo, ambas da linha de produtos mais rústica (figura $4 d$ ).

As tábuas da espécie Nectandra megapotamica (canelinha) apresentaram $24 \%$ de votos negativos. Essa madeira apresenta densidade média a baixa e cor amarelada, mas em algumas amostras o tom foi mais escuro ou até marrom, o que foi de preferência 
dos participantes. Entre as preferidas estavam três tábuas da linha rústica de produtos (figura 4e).

O chapéu-de-sol (Terminalia catappa) apresentou $19 \%$ de respostas negativas. Entre as duas tábuas apresentadas, ambas tiveram número semelhante de votos para preferência (figura 4f). De acordo com a dimensão e forma das amostras disponíveis dessa espécie, pudemos produzir apenas duas tábuas, ambas com design mais rústico. O chapéu-de-sol apresenta densidade média a baixa e coloração marrom escura com desenhos da grã da madeira bem visíveis.

A tipuana (Tipuana tipu) apresentou apenas 8,3\% de rejeição quanto as tábuas produzidas. Ela possui um tom amarelo dourado e densidade baixa. Os protótipos favoritos foram um de design convencional e o outro de design rústico (figura $4 \mathrm{~g}$ ).

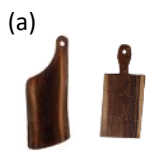

(e)

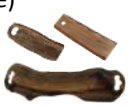

(b)
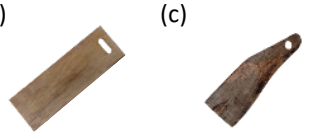

(g)

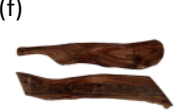

(d)

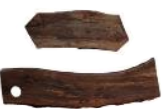

Figura 4: Tábuas preferidas pelo público entrevistado de cada espécie.

Em relação ao material, cores, design, beleza e acabamento das tábuas, foram obtidos os seguintes resultados (Figura 5). O design foi um dos parâmetros que apresentou a menor nota, portanto, é importante que os profissionais da área desenvolvam desenhos mais adequados para esse tipo de produto. No geral, a maioria das notas foram satisfatórias e positivas.

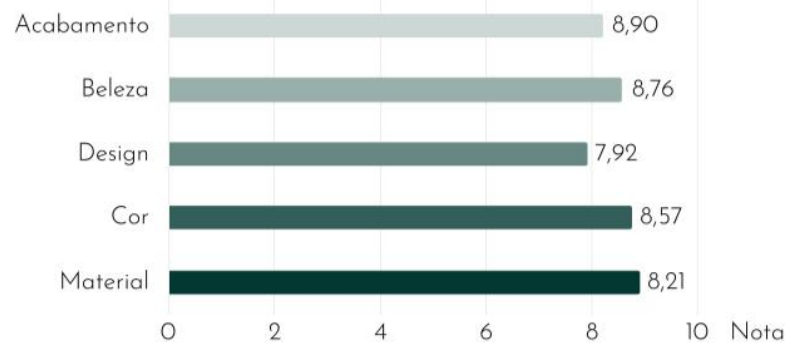

Figura 5: Notas de 0 a 10 para cada característica das tábuas de corte feitas a partir de resíduos.

Em relação às faixas de preço, os participantes votaram que o preço mais adequado para esses produtos seria de até $\mathrm{R} \$ 100,00(90 \%)$, porém alguns disseram que pagariam até mais que o dobro desse valor (5\%). Na pesquisa, $61,2 \%$ dos participantes respondeu que antes de comprar um produto de madeira quer garantir que este está de acordo com as normas ambientais e $38,8 \%$ não observa isso ao comprar produtos.
A maior parte dos participantes prefere madeiras de cores escuras para a confecção desse tipo de objeto $(56,2 \%)$, seguido de madeiras de cores intermediárias $(44,6 \%)$, madeiras de cores claras $(17,4 \%)$ e o restante disse que depende ou que gosta de todas.

A maioria dos participantes não possui restrições quanto ao uso da madeira da poda para a confecção de tábuas de madeira, desde que seja comprovado que estas não façam mal à saúde, ou que haja desenvolvimento de fungos e bactérias. A maioria apoiou a ideia e compraria tábuas confeccionadas a partir dos resíduos da poda e remoção de árvores do ambiente urbano.

Alguns participantes se mostraram contra o uso, argumentando que não se deve remover ou podar as árvores da cidade (1,5\%); e outras não possuem opinião formada sobre o assunto (3,0\%). Dentre os participantes, $99,2 \%$ acreditam que a madeira de poda e remoção de árvores do ambiente urbano tem potencial para o aproveitamento em pequenos objetos de madeira, incentivando o uso e o aproveitamento do material nos comentários.

$\mathrm{Na}$ área de comentários, muitos participantes incentivaram essa pesquisa e o uso dos resíduos para a produção de pequenos objetos de madeira, enfatizando que é uma proposta excelente.

Apenas um participante não acreditou nesse potencial, argumentando que devem ser feitos outros estudos para aprofundar-se nos elementos químicos para identificar possíveis substâncias que possam ser prejudiciais na manipulação e corte de alimentos.

Além dos compostos químicos, outra questão que pode ser mencionada é a higiene das tábuas. Houveram diversos estudos que provaram que a partir de métodos adequados de higienização, as tábuas de madeira são seguras para uso doméstico (Abrishami et al., 1994; Aviat et al., 2016; Milling et al., 2005; Sekoai et al., 2020; Yang et al., 2009). Segundo Snyder Jr (2008), a forma mais correta e efetiva de higienização de tábuas de madeira é através da combinação de peróxido e ácido acético, encontrado em diversos produtos de limpeza vendidos no mercado, pois esse agente pode destruir os microrganismos residuais após o uso.

Cada madeira reage de formas diferentes em contato com alimentos em decorrência dos diversos compostos orgânicos que as constituem e muitas espécies apresentam em sua composição química materiais que podem repelir alguns microrganismos (Ak et al., 1994; Milling et al., 2005). As espécies aqui estudadas são originárias de florestas de regiões tropicais, e apresentam entre 3,38 e 8,83\% de extrativos em sua composição (Klingenberg et al., 2020). Nesse contexto, é interessante realizar mais pesquisas no que tange as propriedades químicas e antissépticas das espécies investigadas. 


\section{CONCLUSÃO}

Conclui-se que as linhas de produtos desenvolvidos a partir dos resíduos de madeira da arborização urbana, as tábuas de corte e servir alimentos, foram bem aceitas pelo público consumidor.

A espécie sibipiruna (Cenostigma pluviosum) teve a maior aceitação dos participantes, seguida do flamboyant (Delonix regia). A coloração, design e forma das tábuas foram fatores decisivos para esses resultados. Dentre as linhas de produtos, rústica e convencional, ambas apresentaram boa aceitação para esse tipo de material, com preferência para a rústica, que trouxe um aspecto positivo em relação ao convencional vendido no mercado, e ressalta o fato do material ser um resíduo.

Portanto, a produção destes pequenos objetos de madeira se apresentou uma forma adequada de valorização e aproveitamento deste material. Incentivamos a realização de pesquisas que avaliem as propriedades físicas, químicas e mecânicas dessa madeira para melhor indicação de uso e aplicação.

\section{AGRADECIMENTOS}

Agradecemos o suporte da Fundação de Amparo à Pesquisa do Estado de São Paulo (FAPESP) - projeto $16 / 14285-5$ e a todos que participaram respondendo os questionários.

\section{REFERÊNCIAS}

1. Ransan, J. \& Figueiredo, A. M. B. (2015). A Arborização Urbana no Município de Chapecó e a Importância do Plantio de Espécies Condizentes ao Local. UCEFF Faculdades, v.3, n.2.

2. Meira, A. M. de. (2010). Gestão de Resíduos da Arborização Urbana. Tese de Doutorado. Universidade de São Paulo (ESALQ/USP), Piracicaba, SP.

3. Shi, Y., Ge, Y., Chang, J., Shao, H., \& Tang, Y. (2013). Garden waste biomass for renewable and sustainable energy production in China: Potential, challenges and development. Renewable and Sustainable Energy Reviews, 22, 432-437.

4. Faraca, G., Boldrin, A., \& Astrup, T. (2019). Resource quality of wood waste: the importance of physical and chemical impurities in wood waste for recycling. Waste Management, 87, 135-147.

5. Pérez-Arévalo, J. J., \& Velázquez-Martí, B. (2018). Evaluation of pruning residues of Ficus benjamina as a primary biofuel material. Biomass and Bioenergy, 108, 217-223.

6. Brasil. (2012). Política Nacional de Resíduos Sólidos. Lei $\mathrm{n}^{\circ}$ 12.305, 2 de agosto de 2010. Presidência da República, Departamento da Casa Civil. Brasília.

7. Araújo, Y. R. V., de Góis, M. L., Junior, L. M. C., \& Carvalho, M. (2018). Carbon footprint associated with four disposal scenarios for urban pruning waste. Environmental Science and Pollution Research, 25(2), 1863-1868.

8. Fetene, Y., Addis, T., Beyene, A., \& Kloos, H. (2018). Valorization of solid waste as key opportunity for green city development in the growing urban areas of the developing world. Journal of Environmental Chemical Engineering, 6(6), 7144-7151.

9. Boumanchar, I., Chhiti, Y., Ezzahrae, F., Alaoui, M., \& Elkhouakhi, M. (2019). Investigation of (co)combustion kinetics of biomass, coal and municipal solid wastes. Waste Management, 97, 10-18.

10. Bispo, L. F. P. (2017). Aproveitamento de Resíduos da Arborização Urbana para a Fabricação de Brinquedos. Trabalho de conclusão de curso. Universidade de São Paulo (ESALQ/USP), Piracicaba, SP.

11. Grohmann, D., Petrucci, R., Torre, L., Micheli, M., \& Meconi, M. E. (2019). Street trees' management perspectives: reuse of Tilia sp.s' pruning waste for insulation purposes. Urban Forestry \& Urban Greening, 38, 177e182.

12. Nowak, D. J., Greenfield, E. J., \& Ash, R. M. (2019). Annual biomass loss and potential value of urban tree waste in the United States. Urban Forestry \& Urban Greening. 46, 126469.

13. Palharini, K. M., Guimarães Junior, J. B., Faria, D. L., Mendes, R. F., Protásio, T. D. P., \& Mendes, L. M. (2018). Potential Usage of The Urban Pruning Residue for Production of Wood Based Panels. Nativa 6, 321.

14. Lopes, C. S. D. (2009) Desenho de Pequenos Objetos de Madeira com Resíduo da Indústria de Processamento Mecânico da Madeira. InterfacEHS, v.4, n.3.

15. Klingenberg, D., Nolasco, A. M., \& Dias Júnior, A. F. (2018). Physical characteristics of seven urban forestry species. Annals of XVI Encontro Brasileiro Em Madeiras e Em Estruturas de Madeira, 1-12.

16. Silva Filho, D. F. (2009). Diagnóstico da Cobertura Arbórea em Tecido Urbano do Município de Piracicaba - SP. Relatório apresentado à Fundação de Estudos Agrários Luiz de Queiroz - FEALQ/Instituto de Planejamento de Piracicaba - IPPLAP. 22p.

17. Klingenberg, D., Nolasco, A. M., Dias Júnior, A. F., Candaten, L., Cavalcante, A. K. L., \& Souza, E. C. De. (2020). Energy potential of wood waste from a tropical urban forest. Research, Society and Development, 9(9). doi: 10.33448/rsd-v9i9.7478

18. Aviat, F., Gerhards, C., Rodriguez-Jerez, J. J., Michel, V., Bayon, I. Le, Ismail, R., \& Federighi, M. (2016). Microbial Safety of Wood in Contact with Food: A Review. Comprehensive Reviews in Food Science and Food Safety, 15(3), 491-505. doi: 10.1111/1541-4337.12199

19. Teixeira, L. V. (2009). Análise Sensorial na Indústria de Alimentos. Rev. Inst. Latic. "Cândido Tostes", Jan/Fev, no 366, 64: 12-21. 
20. Abrishami, Simin H., Tall, B. D., Bruursema, T. J., Epstein, P. S., \& Shah, D. B. (1994). Bacterial Adherence and Viability on Cutting Board Surfaces. Journal of Food Safety, 14(2), 153-172. doi: 10.1111/j.1745-4565.1994.tb00591.x

21. Milling, A., Kehr, R., Wulf, A., \& Smalla, K. (2005). The use of wood in practice - A hygienic risk? Holz Als Roh - Und Werkstoff, 63(6), 463-472. doi: 10.1007/s00107-005-0064-x

22. Sekoai, P. T., Feng, S., Zhou, W., Ngan, W. Y., Pu, Y., Yao, Y., Pan, J., \& Habimana, O. (2020). Insights into the microbiological safety of wooden cutting boards used for meat processing in Hong Kong's wet markets: A focus on food-contact surfaces, crosscontamination and the efficacy of traditional hygiene practices. Microorganisms, 8(4). doi: 10.3390/microorganisms8040579

23. Yang, H., Kendall, P. A., Medeiros, L. C., \& Sofos, J. N. (2009). Efficacy of sanitizing agents against Listeria monocytogenes biofilms on high-density polyethylene cutting board surfaces. Journal of Food Protection, 72(5), 990-998. doi: 10.4315/0362-028X72.5 .990

24. Snyder Jr, P. O. (2008). The evaluation of wooden vs. polyethylene cutting boards using fluorescent powder. HACCP - Hospitality Institute of Technology and Management of St. Paul, MN, 1-3.

25. Ak, N. O., Cliver, D. O., \& Kaspar, C. W. (1994). Cutting boards of plastic and wood contaminated experimentally with bacteria. Journal of Food Protection, 57(1), 16-22. doi: 10.4315/0362-028X57.1.16 